\title{
O potencial formativo dos grupos focais na constituição de educadoras/es ambientais
}

\author{
The formative potential of focal groups \\ in the constitution of environmental educators
}

\author{
Ariane Di Tullio ${ }^{1}$ \\ https://orcid.org/0000-0002-3463-8892 \\ Lakshmi Juliane Vallim Hofstatter ${ }^{2}$ \\ https://orcid.org/0000-0002-6913-3499 \\ Silvia Aparecida Martins dos Santos ${ }^{3}$ \\ https://orcid.org/0000-0002-3327-1128 \\ Haydée Torres de Oliveira ${ }^{2}$ \\ https://orcid.org/0000-0003-3616-6099
}

\begin{abstract}
Resumo: Analisamos neste artigo o potencial formativo da técnica de grupos focais na constituição de educadores ambientais, a partir de três diferentes pesquisas pautadas na perspectiva dialógica crítica. Utilizamos a hermenêutica enquanto modo de interpretação do conjunto dos dados e percebemos, enquanto resultado, que os grupos focais não são permanentes, ao contrário, possibilitam múltiplas construções partilhadas de sentidos, podendo gerar mudanças de posturas pessoais diante da aquisição de novas informações, reflexões e argumentos. Destacamos algumas habilidades de educadoras/ es ambientais, tais como a mediação, a reflexão, a criticidade, o compromisso com a transformação, a alteridade e a flexibilidade que podem ser alcançados com o grupo focal. Dessa forma, observamos o grande potencial formativo dessa técnica quando conduzida de maneira dialógica e participativa.
\end{abstract}

Palavras-chave: Grupos focais. Educação ambiental. Pedagogia dialógica.

\begin{abstract}
In this article, we analyze the formative potential of the focus-group technique in the constitution of environmental educators, based on three different studies grounded on the critical dialogical perspective. We use hermeneutics as a way of interpreting the data and realize as a result that focus groups are not permanent; instead, they allow for multiple shared constructions of meanings, and can generate changes of personal attitudes during the acquisition of new information, reflections and arguments. We highlight some skills of environmental educators, such as mediation, reflection, critical thinking, commitment to transformation, alterity, flexibility, which can be achieved with the focus group. Thus, we realize the great potential of this technique when it is conducted in a dialogic and participative approach.
\end{abstract}

Keywords: Focus groups. Environmental education. Dialogic pedagogy.

\footnotetext{
${ }^{1}$ Fubá Educação Ambiental e Criatividade, São Carlos, SP, Brasil. E-mail: ariane@fubaea.com.br.

${ }^{2}$ Universidade Federal de São Carlos (UFSCar), Programa de Pós-Graduação em Ecologia e Recursos Naturais, São Carlos, SP, Brasil.

${ }^{3}$ Universidade de São Paulo (USP), Centro de Divulgação Científica e Cultural, São Carlos, SP, Brasil.
} 


\section{Introdução}

A educação ambiental (EA) encontra-se em processo de construção e legitimação enquanto campo de práticas e de conhecimento (CATANI, 2009), tanto em âmbito nacional quanto internacional, o que se traduz na busca por um aprofundamento na compreensão e coerência entre seus pressupostos teóricos e fundamentos metodológicos (FERNANDES; KAWASAKI, 2012; PAYNE, 2009; REID; SCOTT, 2006).

Seguindo essa tendência internacional de consolidação do campo, no Brasil também houve um aumento expressivo das pesquisas em EA, especialmente a partir da década 1990, (CARVALHO; TOMAZELLO; OLIVEIRA, 2009; FRACALANZA et al., 2005), o que gerou subsídios para melhor compreender a amplitude que o campo vem ganhando. Hoje temos um banco de dados da produção acadêmica na área, resultado do projeto sobre o Estado da Arte em EA (EArte), envolvendo três universidades: Universidade Estadual de Campinas (UNICAMP), Universidade de São Paulo (USP) e Universidade Estadual Paulista "Julio de Mesquita Filho" (UNESP).

Observa-se que a pesquisa em EA, assim como a pesquisa educacional em sentido amplo, tem sido fundamentada em uma diversidade de métodos e técnicas, comumente agrupados em torno de três grandes paradigmas: o positivismo/pós-positivismo, o interpretativismo/ construtivismo e o crítico/marxista (FIEN, 2002; ROBOTTOM; HART, 1993), também chamados, respectivamente, de pesquisa como evidência, pesquisa como coaprendizado, e pesquisa como ativismo por Dillon e Wals (2006). Alguns autores ainda definem um quarto paradigma, o pós-moderno ou pós-estrutural (FIEN, 2002), do qual derivam novas formas de pensar e fazer EA (STEIL; CARVALHO, 2014), mais pautadas nos sentidos (PINK, 2009), nas experimentações (CARVALHO; MHULE, 2016; PAYNE; WATTCHOW, 2009), na relativização do tempo e das verdades (INGOLD, 2010) e na tendência crescente da teoria não-representacional (THRIFT, 2008). Em meio a essa diversidade de paradigmas, há uma preocupação em assegurar a coerência entre objetivos, métodos e procedimentos de pesquisas (PAYNE, 2005).

Desde o primeiro Encontro de Pesquisa em EA (EPEA) no Brasil, em 2001, é notável a tendência crescente em fundamentar as pesquisas dentro do paradigma interpretativo/ construtivista e, consequentemente, realizar a coleta de dados de caráter textual, por meio de narrativas, discursos, entrevistas e observações que implicam na ampliação da compreensão da realidade (TOZONI-REIS; SOUZA, 2014).

Temos observado um aumento no número de pesquisas (BERTO; CRIBB, 2008; NEIMAN; RABINOVICH, 2008, entre outras) que têm utilizado os grupos focais como estratégia de coleta de dados. No entanto, muitas delas estão centradas apenas nas técnicas, e desvinculadas do referencial teórico que, inclusive, várias vezes não é explicitado.

Considerando esse aumento do número e da diversidade das pesquisas em EA e a necessidade de fortalecer o campo metodologicamente e epistemologicamente em suas inter -relações, este artigo tem como objetivo apresentar e discutir a dimensão educativa e formativa da técnica dos grupos focais, mesmo que não intencional, a partir dos resultados de três pesquisas realizadas pelas autoras deste artigo, com diferentes sujeitos e em diferentes contextos (DI TULLIO; OLIVEIRA, 2014; HOFSTATTER, 2013; SANTOS, 2010).

A primeira pesquisa (SANTOS, 2010) teve como foco de estudo a análise do processo formativo promovido pelo Coletivo Educador São Carlos, Araraquara, Jaboticabal e 
Região (CESCAR). Este coletivo foi constituído no contexto do Programa de Formação de Educadoras/es Ambientais (ProFEA), política pública formulada pelo Departamento de EA do Ministério do Meio Ambiente (DEA/MMA). A metodologia proposta pelo ProFEA é formar uma rede de capilaridade na qual os chamados PAP (grupos de pesquisa-ação-participativa/pessoas que aprendem participando), formados por PAP1 (órgão gestor) e PAP2 (instituições parceiras do coletivo) se colocam o desafio de formar os grupos PAP3 (lideranças comunitárias, professores, técnicos de organizações governamentais e não governamentais etc.) que têm como missão formar os grupos PAP4 (educadores ambientais populares) (BRASIL, 2006). A implementação do CESCAR se deu por meio dos cursos de extensão e especialização, que foram realizados concomitantemente e oferecidos oficialmente pela Pró-Reitoria de Extensão da Universidade Federal de São Carlos, em parceria com as outras instituições que fizeram parte do CESCAR, durante o período de janeiro de 2007 a setembro de 2008. Participaram do processo como PAP2 49 pessoas representando 38 instituições parceiras de 11 municípios da região, e como PAP3, 75 pessoas, sendo 57 estudantes de especialização e 18 de extensão.

A segunda pesquisa, de Hofstatter (2013), ocorreu no semiárido baiano, com professoras/es do ensino básico de uma comunidade caatingueira, entre 2011 e 2013. O objetivo da pesquisa foi desvelar as percepções socioambientais sobre a caatinga e sobre as onças (Panthera onca; Puma concolor) que habitam a região. O trabalho ocorreu com um grupo de 25 pessoas, sendo 19 professoras/es e 6 integrantes da comunidade de Brejo dos Olhos d'Água que tiveram interesse espontâneo em participar. O formato proposto foi um curso de EA, em sua perspectiva crítica, pautado em metodologias participativas. Foram desenvolvidas, durante os 4 encontros com a turma, as temáticas propostas previamente pela pesquisadora, que atendiam ao intuito da pesquisa, além das que emergiram durante o processo formativo.

A terceira pesquisa (DI TULLIO; OLIVEIRA, 2014) foi desenvolvida no contexto do Projeto ProMEA na Rede, implementado em 2011 e 2012 pela Prefeitura Municipal de São Carlos, SP, por meio da Secretaria Municipal de Educação e da Coordenadoria de Meio Ambiente. Seu objetivo principal era institucionalizar a EA enquanto política pública dentro da rede municipal de ensino, visando ao enraizamento das ações, projetos e programas de EA na rede municipal de ensino e na sociedade sancarlense. Para isso, foram selecionadas algumas professoras do ensino básico (infantil e fundamental) que dedicavam parte da sua jornada de trabalho para atuar como educadoras ambientais nas escolas em que lecionavam. A investigação realizada nesse contexto buscou compreender o processo de formação dessas professoras na sua atuação como educadoras ambientais.

Nos dois itens a seguir apresentamos os referenciais teórico-metodológicos da pesquisa para, a partir deles, explicitarmos o percurso metodológico e os resultados obtidos.

\section{A dimensão dialógica na perspectiva da formação de educadoras/es}

O campo da EA se constituiu conjuntamente ao movimento ambientalista, ganhando espaço nos encontros internacionais ocorridos na década de 1970. Dessa maneira, as primeiras pessoas que se tornaram educadoras/es ambientais foram as engajadas no movimento ambientalista, que começam a organizar princípios e práticas relacionadas à formação e divulgação da EA (GUIMARÃES, 2004). 
A formação na área vem aumentando consideravelmente nas últimas décadas e ocorre tanto por meio de espaços informais de ensino, como organizações não governamentais e espaços de participação política, quanto em cursos de diferentes modalidades e duração, oferecidos por instituições formais e não formais de ensino. O campo também avançou na constituição legal, sendo que, no ensino básico, sua inserção nos currículos é garantida por lei, de maneira interdisciplinar. No ensino superior, pode ser ofertada de maneira disciplinar quando se objetiva um conhecimento metodológico e técnico da área. Já sua inserção na pósgraduação traz dois aspectos que merecem ser considerados. O primeiro é que passamos a ter docentes doutoras/es na área. O segundo é a amplitude dos novos conhecimentos e de sua constituição enquanto campo epistêmico e de pesquisa.

Antes de tratar da formação de educadoras/es ambientais na perspectiva dialógica que adotamos, achamos necessário situar nossa compreensão do que seja diálogo. Entendemos o diálogo como uma condição mínima e fundamental nos processos formativos. Segundo Freire (2012, p. 122), a comunicação é um fator gerador de vida, pois “a dialogicidade é uma exigência da natureza humana, de um lado; de outro, um reclamo de opção democrática do educador. No fundo, não há comunicação sem dialogicidade e a comunicação se acha no centro mesmo do fenômeno vital".

Também contemplamos o entendimento de diálogo verdadeiro apresentado por Hans-Georg Gadamer (GADAMER, 2005) como aquele que acontece no encontro entre pessoas dispostas a ouvirem-se mutuamente e expor suas opiniões, sem que uma tente derrotar a outra, mas possibilitando uma autorreflexão sobre seus pontos de vista.

Assim, entendemos a formação de educadoras/es ambientais como a formação de sujeitos para atuar como mediadoras/es de processos educativos com foco na dimensão ambiental e trazer os aspectos reflexivos e críticos para suas atuações. Valorizamos os saberes produzidos pelas/os educadoras/es a partir das suas experiências, para além da mera aplicação do conhecimento (CONTRERAS, 2012; NÓVOA, 1992).

Adotamos a concepção de educador/a como intelectual crítica/o, de Henry Giroux, por considerarmos a mais adequada à perspectiva crítica, propondo que a reflexão vá além das práticas pedagógicas e promova um (re)pensar sobre o papel do/a educador/a na escola e na sociedade (GIROUX, 1997). Esse tipo de reflexão considera os seres humanos em suas relações com o mundo, pois eles pertencem à história muitos antes de serem capazes de refletir sobre ela (GADAMER, 2005). Essa concepção também é compartilhada por Freire (2000, p. 40): "não apenas temos história, mas fazemos a história, que igualmente nos faz e que nos torna, portanto históricos". Assim, os humanos são seres inacabados, vivendo uma realidade histórica igualmente inacabada (FREIRE, 1980).

Deste modo, a reflexão proposta no processo de formação de educadoras/es assume sua dimensão político-ideológica: as/os educadoras/es vão gradativamente adquirindo clareza dos seus referenciais políticos e morais e, consequentemente, assumindo um compromisso com a construção de um saber crítico e com a transformação social (FREIRE, 1994; GIROUX, 1997). Por aspirar a uma finalidade, a formação não pode ser reduzida apenas aos seus aspectos técnico-científicos, ou seja, ela deve possibilitar a apreensão dos conhecimentos fundamentais do campo em questão, mas também construir uma compreensão crítica da presença da/o educador/a no mundo (FREIRE, 2000). Ela deve desafiá-la/o a refletir sobre a sua realidade social, política e histórica a partir da problematização de situações concretas e 
do diálogo com outras pessoas (FREIRE, 1980). Nessa perspectiva, os processos educativos devem estar baseados na crítica, mas também na possibilidade (GIROUX, 1997), o que Freire (2000) caracteriza como denúncia e anúncio.

$\mathrm{Na}$ perspectiva crítica o aprendizado ocorre a partir da experiência, da reflexão e da confrontação do sujeito consigo mesmo, com suas crenças e opiniões (HERMANN, 2002), de maneira que "educar é educar-se" (GADAMER, 2011, p. 92). Isso não significa um processo individualista, ao contrário, ele acontece por meio do diálogo com o outro (GADAMER, 2011). De acordo com sua historicidade e seus preconceitos, cada pessoa possui um horizonte de mundo (LAWN, 2010), sendo que o entendimento ocorre quando o horizonte de uma pessoa se coloca em contato com o de outra pessoa e ocorre um processo de fusão de horizontes, no qual ambos se integram (GADAMER, 2005; TESTA, 2004), produzindo novos significados (GADAMER, 2005; LAWN, 2010). Dessa maneira, a compreensão acontece no diálogo e, portanto, nessa perspectiva, a dimensão coletiva das práticas reflexivas das/os educandas/os é valorizada. É preciso respeito pela dignidade e alteridade do outro e abertura para a possibilidade de mudar suas próprias convicções (FREIRE, 1994; HERMANN, 2002).

O diálogo também é central na perspectiva freiriana: “o educador já não é o que apenas educa, mas o que, enquanto educa, é educado em diálogo com o educando que ao ser educado também educa" (FREIRE, 1980, p. 78). Assim, educadoras/es e educandas/os se tornam sujeitos do processo educativo, que não se constitui apenas em transferência de saber, mas no encontro de sujeitos interlocutores que buscam (re)construir sentidos e significados (FREIRE, 1985). Por fim, a formação profissional da/o educador/a (que não pode ser separada da sua formação pessoal) está intimamente ligada à produção de sentidos sobre suas vivências e experiências pessoais e profissionais (HERMANN, 2002; NÓVOA, 1992).

\section{Os grupos focais}

A técnica dos grupos focais foi inicialmente utilizada na área do marketing na década de 1920 (GATTI, 2005). Em 1950, Paul Lazarsfeld e Robert Merton a transpuseram para verificar fatores influentes na audiência de uma rádio. Eles intuíram que uma entrevista focalizada em grupo traria melhores resultados do que as entrevistas individuais, ao constatarem o poder dos insights gerados no contexto coletivo (MORGAN, 1996).

Na década de 1980 essa técnica passou a ser cada vez mais utilizada em pesquisas da área de saúde e, posteriormente, nas ciências sociais e humanas com a finalidade de conhecer diferentes ideias, perspectivas, sentidos e compreensões que um determinado grupo possa ter a respeito de um tema (GATTI, 2005). Sua principal característica é a interação entre as/os participantes (BARBOUR, 2009; KRUEGER, 1994; MORGAN, 1996), o que permite que o/a pesquisador/a conduza o foco da discussão (MORGAN, 1996), compreendendo as ideias compartilhadas e o modo pelo qual as pessoas se influenciam mutuamente (GATTI, 2005).

Embora a entrevista individual seja compreendida como um momento de interação entre entrevistador/a e entrevistada/o, no qual ambas/os dialogam sobre as experiências vividas construindo significados conjuntos (ROLLEMBERG, 2013), no grupo focal há uma variedade maior de interlocutores/as, ampliando, portanto, os significados a respeito do objeto de estudo. Outra característica que distingue o grupo focal das outras formas de entrevista é que eles não pretendem uma amostragem ou formulação de respostas específicas, mas sim 
a compreensão da dinâmica grupal. Por fim, Morgan (1996) argumenta que as entrevistas se constituem de maneira mais formal do que são os grupos focais.

Nos grupos focais, as falas produzidas se influenciam no conjunto interatuante do grupo ou promovem insights entre as/os participantes. Gaskell (2010, p. 75) descreve que "é mais do que a soma das partes: ele se torna uma entidade em si mesma". À/ao pesquisador/a cabe procurar compreender os efeitos das vivências do grupo sobre as trocas entre as/os participantes, os consensos, os dissensos, as rupturas e os silenciamentos (GATTI, 2005).

Segundo Cruz Neto, Moreira e Sucena (2002, p. 5), a técnica dos grupos focais não é adequada para entender a concepção individual das pessoas, pois a "fala" que é trabalhada nos grupos focais não é meramente descritiva ou expositiva; ela é uma "fala em debate", na qual todos os pontos de vista expressos devem ser discutidos pelos participantes.

A constituição e o desenvolvimento do grupo focal devem considerar o problema da pesquisa e o referencial teórico do trabalho, ou seja, deve haver coerência entre o uso dessa técnica, os objetivos e o delineamento teórico-metodológico da pesquisa (GATTI, 2005). No caso das três investigações descritas neste artigo, consideramos que essa coerência é observada, pois todas estão baseadas em referenciais dialógicos da pesquisa em EA.

Assim, podemos dizer que o grupo focal possui como potencial a construção coletiva de ideias e significados, a partir da variedade de pontos de vista sobre uma questão (mesmo que dentro de um contexto social específico). Pode-se dizer que todo o grupo se envolve na produção do conhecimento, mesmo que de maneiras diferentes (GASKELL, 2010). Tozoni-Reis (2007) apresenta diversos argumentos em defesa da construção coletiva de conhecimentos, perspectiva coerente com uma abordagem participativa e reflexiva em EA, comprometida com transformações de cunho socioambiental. Segundo o autor, qualquer transformação social só é possível a partir do agrupamento e das relações que se estabelecem entre as pessoas, nos provocando a aprofundar a compreensão do potencial e do sentido grupal das interações humanas. Segundo ele, "o grupo em si mesmo não garante transformações, mas cria condições de possibilidade para que ela aconteça”. (TOZONI-REIS, 2007, p. 83-84).

O grupo focal tem sido muito utilizado para avaliação/compreensão dos resultados de processos de formação e intervenção em EA. No entanto, poucos são os estudos que tratam da sua dimensão formativa. Gatti (2005, p. 13) defende que "a participação em um processo de grupo focal também pode propiciar um momento de desenvolvimento para os participantes, tanto nos aspectos comunicacionais, como cognitivos e afetivos". De acordo com a autora e observando as características anteriormente descritas dos grupos focais, partimos do pressuposto que, mais do que uma técnica de coleta de dados, eles também podem ser considerados momentos de formação das/os participantes em uma perspectiva dialógica.

\section{Descrição metodológica e corpus de análise}

A literatura indica que os grupos focais devem ser conduzidos por, no mínimo, duas/ ois pesquisadoras/es, pois existem as funções de mediador/a, observador/a e operador/a de gravação, além da posterior transcrição (CRUZ NETO; MOREIRA; SUCENA, 2002). Na investigação realizada no contexto do CESCAR, a pesquisadora contou com a ajuda de duas outras pessoas que fizeram anotações a respeito da dinâmica grupal. Porém, nas demais pesquisas, isso não foi possível porque havia somente uma pesquisadora em campo. Nesses casos, 
as pesquisadoras assumiram tanto a função de mediadoras, conduzindo o debate em alguns momentos em que percebiam a necessidade de intervenção por diferentes motivos (concentração de fala, mudança de foco, necessidade de aprofundamento de determinadas temáticas), como o papel de observadoras enquanto a discussão fluía (observando as expressões, falas, posturas e fazendo anotações do processo).

Um dos pontos importantes do grupo focal que procuramos atender foi o número de participantes. Ele não deve ser muito pequeno, para permitir uma melhor interação grupal e a emergência de diferentes visões sobre as questões tratadas, mas também não deve ser tão grande, para que todas as pessoas tenham voz e a possibilidade de se expressar. Assim, o número máximo indicado na literatura é de até 12 pessoas (CRUZ NETO; MOREIRA; SUCENA, 2002; KITZINGER; BARBOUR, 1998). Também é necessário observar a origem do grupo (se as pessoas se conhecem previamente ou não) e escolher um ambiente propício para instigar o diálogo (KITZINGER; BARBOUR, 1998). Existe uma recomendação de que os grupos focais sejam formados com pessoas que tenham semelhantes contextos de vida ou de atuação, mas não devem ser homogêneos em atitudes, opiniões ou comportamentos, favorecendo a diversidade (BARBOUR, 2009).

Coerentemente com as diretrizes sugeridas por Kitzinger e Barbour (1998) e Krueger, (1994) para o planejamento, condução e realização dos grupos focais, elaboramos um roteiro flexível em relação à sequência das respostas, com questões-chave que tinham por objetivo uma avaliação das experiências vivenciadas e o levantamento de informações elucidativas dos processos formativos vividos. A excessiva estruturação do grupo focal "com roteiros rigorosos, etapas a serem cumpridas e modo perguntas e respostas" prejudica a criação de uma rede interativa, gerando diálogos polarizados entre mediador/a e participante, com reflexões superficiais e pouco esclarecedoras sobre o tema. Assim, as interações ocorrem em situações limitadas, o que também restringe suas análises (GATTI, 2005).

Segundo Cruz Neto, Moreira e Sucena (2002), o roteiro de debate é o parâmetro utilizado pela mediadora para conduzir o grupo focal e, portanto, não deve ser monolítico e nem estático. Por isso, o papel de mediadora ou moderadora é fundamental, pois potencializa a comunicação entre as/os participantes, ajudando a consolidar a interação social, operando sentidos e representações que emergem pela natureza social do grupo. "Um bom tópico guia irá criar um referencial fácil e confortável para uma discussão, fornecendo uma progressão lógica e plausível através dos temas em foco. Ele funciona como um esquema preliminar para análise das transcrições" (GASKELL, 2010, p. 67).

Nas três pesquisas, os grupos focais se iniciaram com a solicitação de que as pessoas respondessem individualmente ao roteiro de questões, com a finalidade de que as respostas prévias ao diálogo ficassem registradas, facilitando a organização e coleta de dados do grupo. As respostas dadas individualmente por meio do roteiro de questões foram posteriormente tabuladas. Após os roteiros serem respondidos, iniciou-se o diálogo, sendo que cada participante discorreu e aprofundou os conteúdos registrados na etapa anterior. Os diálogos foram gravados em áudio e depois transcritos integralmente.

Ressaltamos que, embora o corpus de análise deste artigo (o resultado das transcrições dos grupos focais e respostas do roteiro tabuladas) seja o mesmo de cada uma das três pesquisas originais, aqui o olhar recai sobre a interação entre os participantes e o processo de constituição de educadoras/es em uma perspectiva dialógica, o que difere substancialmente da 
maneira pela qual os dados foram analisados em publicações anteriores (que cumpriam um papel de analisar o processo formativo - primeira e terceira pesquisa e investigativa na segunda).

Utilizamos, como técnica de análise dos dados, a Análise Textual Discursiva, considerada um tipo de Análise de Conteúdo em que há uma valorização tanto da descrição como da interpretação enquanto partes do processo compreensivo, assim como uma busca da construção e reconstrução de compreensões sociais a partir das manifestações discursivas dos sujeitos da pesquisa (MORAES; GALIAZZI, 2011). Sua primeira etapa consistiu na fragmentação do corpus em unidades de sentido, de acordo com o objetivo proposto nesta pesquisa. Em segui$\mathrm{da}$, foram criadas as categorias, ou seja, as unidades de sentido anteriormente definidas foram agrupadas com base em aspectos semelhantes.

De acordo com o referencial teórico adotado, optamos pelo uso de categorias emergentes, o que permitiu identificar algumas subjetividades manifestadas pelas pessoas. As categorias também não são mutuamente exclusivas, sendo que algumas unidades de sentido podem ser compreendidas em mais de uma delas. Além disso, a proximidade das pesquisadoras com os grupos trouxe outros elementos para a interpretação, que se baseia nos materiais do corpus, mas também nas vivências acumuladas ao longo do processo.

Esse artigo não tem a intenção de tratar das contribuições e limitações dos grupos focais enquanto técnica de coleta de dados científicos, o que já foi discutido por vários autores citados anteriormente (BARBOUR, 2009; GASKELL, 2010; GATTI, 2005; KITZINGER; BARBOUR, 1998; KRUEGER, 1994; MORGAN, 1996). Em vez disso, optamos por fazer uma reflexão sobre seu potencial para a formação de educadoras/es ambientais em uma perspectiva dialógica, a partir dos resultados de três pesquisas realizadas pelas autoras deste artigo (DI TULLIO; OLIVEIRA, 2014; HOFSTATTER, 2013; SANTOS, 2010).

\section{Coletivo Educador São Carlos, Araraquara, Jaboticabal e Região (CESCAR)}

Nessa pesquisa os grupos focais foram realizados com o objetivo de avaliar o processo formativo segundo a visão dos próprios participantes. Foram convidados a participar todos os PAP2 e PAP3, sendo considerada a adesão espontânea o critério de seleção para a participação na pesquisa. Desta forma, foram realizados cinco grupos focais durante o período de abril de 2009 a março de 2010, com 34 participantes envolvidas/os.

O tópico-guia contava com os seguintes itens: expectativas em participar do processo, dificuldades encontradas, contribuições para a vida pessoal e profissional, momentos que se sentiu parte do CESCAR e perspectivas de continuidade, tanto com relação ao projeto de interação educativa desenvolvido durante o processo como ao próprio CESCAR.

\section{Formação de professoras/es no semiárido baiano}

$\mathrm{Na}$ pesquisa ocorrida no semiárido baiano, também foram realizados dois grupos focais no último encontro com as/os participantes em março de 2013. Utilizou-se a técnica do grupo focal para aprofundar e discutir algumas questões que se mostraram necessárias durante o decorrer de todo o curso; estas foram questões que atrelavam a utilização dos recursos naturais na caatinga à tolerância e aceitação da onça. Cada uma das questões formuladas trouxe, enquanto intencionalidade, temas pertinentes suscitados pelas/os participantes e isso foi exposto ao grupo no início do trabalho do grupo focal. 
O primeiro grupo foi formado por dez pessoas que tiveram contato direto com a onça ou descrito por pessoa muito próxima (morador da mesma casa), o que significa que ou ocorreu um encontro ocasional frente a frente com o animal, uma vez que existe aproximações dos animais na comunidade ou em alguma ocasião das pessoas estarem nas regiões de mata, ou, ainda, esse encontro foi compartilhado de maneira intensa por alguém muito próximo, como exemplo o pai de uma participante que encontrou uma onça no quintal de sua casa, o que permitiu que a entrevistada relatasse detalhadamente diversos aspectos/sentimentos desse encontro. O segundo grupo foi composto por 10 pessoas que não tiveram contato direto e mais um integrante que teve contato direto com a onça; porém, ele não pôde participar do primeiro grupo por incompatibilidade de horário e o segundo grupo totalizou, assim, onze participantes. A questão do contato ou não com a onça nos pareceu uma questão de muita importância para ser analisada em grupos diferentes, pois queríamos investigar se o contato direto influenciava na forma como as pessoas percebem a onça e, efetivamente, constatamos que influenciou.

O roteiro elaborado conteve questões-chave que proporcionaram o levantamento de informações elucidativas; porém, a discussão não foi estática, pelo contrário, permitiu a livre manifestação e emergência de informações complementares e importantes para a discussão.

\section{Projeto ProMEA na Rede (São Carlos, SP)}

Durante a coleta de dados da pesquisa vinculada ao projeto ProMEA na Rede, foram realizados três grupos focais, um deles em novembro de 2011 e dois em dezembro de 2012. Todos tinham como finalidade avaliar as atividades desenvolvidas ao longo dos referidos anos. Em 2011, o grupo focal contou com 9 pessoas. Destas, 6 eram professoras que atuavam como educadoras ambientais locais, 2 eram gestoras municipais e a pesquisadora. Em 2012, um dos grupos focais envolveu as nove professoras que atuavam como educadoras ambientais em suas escolas no período da manhã e outro teve como participantes as oito educadoras ambientais do período da tarde. As temáticas propostas versavam sobre as contribuições do projeto para a EA escolar e para as microbacias envolvidas, as dificuldades enfrentadas e as propostas para sua continuidade no ano seguinte.

Nas três pesquisas, a técnica de grupos focais foi utilizada ao final do processo, com a finalidade de coletar dados para compreender as experiências vivenciadas pelas/os participantes. Nas pesquisas realizadas no âmbito do CESCAR e do ProMEA na Rede, os grupos focais tinham finalidade avaliativa, o que, segundo Gatti (2005), restringe um pouco o diálogo. Isso porque, nesse caso, os objetivos da avaliação determinam os pontos específicos de fala, sendo que nessas condições, em geral, as análises são mais estruturadas. No entanto, essa técnica foi intencionalmente escolhida para, além de permitir a coleta de dados, possibilitar que as/os participantes pudessem compartilhar suas experiências.

\section{Resultados e discussão: o potencial dos grupos focais para a for- mação de educadoras/es ambientais em uma perspectiva dialógica}

Nas três pesquisas descritas, observamos a importância dos grupos focais como técnica de coleta de dados e destacamos seu potencial formativo em uma perspectiva dialógica. $\mathrm{O}$ 
quadro 1 ilustra a associação feita pelas autoras entre alguns atributos (características e habilidades) considerados importantes para educadoras/es ambientais em uma vertente dialógica e as contribuições dos grupos focais para o desenvolvimento de tais particularidades, identificadas nas três pesquisas analisadas.

Quadro 1 - Aspectos formativos presentes nos grupos focais

\begin{tabular}{|l|l|}
\hline $\begin{array}{c}\text { Características e habilidades importantes às/aos } \\
\text { educadoras/es ambientais em uma vertente dialógica }\end{array}$ & \multicolumn{1}{c|}{ Contribuições dos grupos focais } \\
\hline Sujeitos abertos a ouvir e mudar suas próprias convicções & $\begin{array}{l}\text { Influências recíprocas e reelaborações de } \\
\text { posicionamentos individuais }\end{array}$ \\
\hline Sujeitos comprometidos com a transformação social & Engajamento político \\
\hline Sujeitos reflexivos & $\begin{array}{l}\text { Oportunidade de refletir individualmente sobre a } \\
\text { temática em um contexto de grupo }\end{array}$ \\
\hline $\begin{array}{l}\text { Sujeitos que respeitam a alteridade e valorizam os saberes/ } \\
\text { experiências das outras pessoas }\end{array}$ & $\begin{array}{l}\text { As construções compartilhadas de sentidos, } \\
\text { opiniões e conhecimentos }\end{array}$ \\
\hline Sujeitos mediadores & Habilidade de lidar com conflitos \\
\hline Sujeitos críticos & $\begin{array}{l}\text { Possibilidade de comparar e confrontar opiniões } \\
\text { diversas dentro do grupo, assumindo uma posição }\end{array}$ \\
\hline
\end{tabular}

Fonte: elaborado pelas autoras.

Os subitens a seguir representam as categorias que criamos a partir do agrupamento das unidades de sentido identificadas nos grupos focais analisados. Buscamos apresentar os elementos identificados explicitando suas contribuições para a formação de educadores ambientais em uma perspectiva dialógica. Lembramos que tais categorias não são mutuamente exclusivas e que muitos dos elementos podem ser classificados em mais de uma delas.

\section{Influências recíprocas e reelaborações de posicionamentos individuais}

Em todas estas pesquisas, pudemos perceber algum tipo de influência entre as/os participantes. Na segunda pesquisa, por exemplo, em um primeiro momento da discussão, todos as/os integrantes do grupo disseram ser repugnante matar a onça sem que ela ameaçasse diretamente a vida humana. Porém, quando uma participante afirmou que uma onça que compete pelos recursos naturais com os seres humanos, como a predação ao rebanho, de maneira indireta ameaça a vida humana e, neste caso, também se justificaria sua morte, todas/ os do grupo ressignificaram suas respostas iniciais e passaram a naturalizar a morte da onça em retaliação. Este aspecto é muito interessante, pois demonstra que, a partir de um elemento que passou a ser considerado pelo grupo, as opiniões se modificaram através de uma nova conjectura. Como descrito por Barbour (2009), uma fala serve como disparador de pensamentos, reflexões, discussões e posicionamento de pessoas mais silenciosas que sentem mais conforto em se manifestar quando respaldadas por um grupo. Ainda segundo o autor, "os grupos focais deveriam ser valorizados por sua capacidade única de fornecer o entendimento de como essas visões se formam" (BARBOUR, 2009, p. 58). 
Também na segunda pesquisa observamos a mudança de posicionamento no decorrer da discussão entre as participantes em relação ao que foi respondido individualmente no registro inicial, de modo que as informações foram se complementando e as ideias foram sendo reformuladas. Uma pessoa que inicialmente havia respondido que não queria a presença da onça na comunidade, em conversa posterior no grupo argumentou que sua resposta foi pensando nos outros. Ele afirmou que o curso contribuiu para desmistificar o medo excessivo, mas como os outros têm medo, melhor que a onça não esteja por perto. O diálogo possibilitou ao participante uma melhor reflexão de sua resposta e talvez até uma reelaboração de seu sentimento em relação à aceitação da onça. $\mathrm{Na}$ análise da interação grupal, é importante examinar também as vozes individuais na discussão (BARBOUR, 2009), o que poderia nos permitir vislumbrar as possibilidades de transformação, sejam individuais, sejam no âmbito coletivo, que essas interações podem fomentar (TOZONI-REIS, 2007). Assim, observamos que "os comentários feitos durante os grupos focais são altamente dependentes do contexto e são contingentes às respostas dos membros do grupo, às contribuições dos outros e à dinâmica daquele grupo em particular" (BARBOUR, 2009, p. 56).

\section{Dimensão política e de engajamento da formação}

Durante o grupo focal de avaliação do processo formativo promovido pelo CESCAR, realizado entre os membros da equipe coordenadora, surgiu uma proposta de reorganização do coletivo para dar continuidade às atividades. O grupo focal com a equipe coordenadora foi realizado depois dos grupos focais com os participantes do curso, sendo que grande parte da equipe esteve presente em ambos os momentos. Assim, a partir das dificuldades relatadas nos primeiros grupos focais com relação ao tamanho do grupo e à distância entre os municípios, o Núcleo Gestor de São Carlos sugeriu reorganizar o CESCAR localmente, junto com outras iniciativas como a Rede de EA (REA-SC) e o projeto São Carlos CRIA Sala Verde, do qual já participavam várias instituições que também faziam parte do Coletivo (SANTOS, 2010). Johnson (1996 apud BARBOUR, 2009, p. 3) destaca a importância do grupo focal para estimular mudanças significativas e levar as/os participantes a redefinir seus problemas de uma forma mais politizada, podendo se configurar como um espaço de engajamento social e político.

Destacar a dimensão participativa e dialógica dos processos formativos que assumimos e que permitiu uma livre fluência entre as/os participantes nos grupos focais no final do processo contrapõe a posição de Gatti (2005) de que os grupos devem ser formados por pessoas que não possuem intimidade para não haver subgrupos, monopolização ou paralisação da discussão além de coibir ou inibir a manifestação de ideias diversas.

Nesse sentido, no final do primeiro ano de implementação do projeto ProMEA na Rede, foi realizado um grupo focal com todas as participantes (educadoras ambientais e gestoras) com a finalidade de avaliar as atividades desenvolvidas até então. Esse grupo focal trouxe resultados bastante importantes que possibilitaram (re)direcionar o foco das ações no ano seguinte. No entanto, o clima foi muito tenso. Segundo relatos da pesquisadora em seu diário de campo, logo no início da atividade já foi possível perceber uma polarização entre as duas gestoras, o que se manifestou fisicamente pela ocupação de posições opostas entre ambas na mesa. O diálogo tinha como foco o papel das educadoras ambientais no projeto, sendo que uma defendia uma função mais pragmática e a outra defendia a articulação de ações e políticas públicas. 
O fato de uma delas exercer uma função hierarquicamente superior às professoras inibiu a livre manifestação das ideias de algumas delas, como relatado à pesquisadora ao final da atividade.

Embora o debate a respeito do papel das educadoras no contexto do projeto tenha sido legítimo e, devido à sua importância, tenha se estendido para além do grupo focal, acreditamos que a mera divergência de opiniões entre as gestoras não foi a única razão do embate travado naquele momento. Divergências pessoais entre as duas participantes promoveram um acirramento das posições, levando ao aumento do clima de tensão no grupo. No caso dessa pesquisa, como o grupo focal foi realizado na casa de uma das professoras, quando as discussões começaram a ficar tensas, ela se encarregou de servir um lanche ao grupo, com a finalidade clara (e posteriormente explicitada) de amenizar a tensão e promover uma situação mais agradável. Barbour (2009) afirma que desacordos podem ser ótimos recursos para análise, mas o moderador precisa perceber e explorar as razões por trás das diferenças de opinião e, muitas vezes, os próprios participantes do grupo ajudam a lidar com os conflitos que surgem.

\section{Oportunidade de refletir individualmente sobre a temática em um contexto de grupo}

$\mathrm{Na}$ terceira pesquisa, também percebemos uma reelaboração do pensamento de uma professora por meio da sua fala no grupo focal. Quando questionada se ela sentiu alguma resistência ao seu trabalho em algumas escolas, em um primeiro momento ela afirmou que não tinha certeza se foi bem isso. Em seguida, ela desenvolveu sua fala, descrevendo e exemplificando as situações e experiências que vivenciou nesse sentido e por fim concluiu que houve sim resistência. Talvez a professora não houvesse pensado nessa questão anteriormente e acreditamos que o grupo focal criou oportunidade para essa reflexão. Coerentemente com o referencial teórico anteriormente explicitado, os grupos focais estudados nos possibilitaram reconhecer a relação intrínseca que existe entre pensamento e fala, ou seja, a palavra não é resultado do pensamento, mas ambos se formam simultaneamente (HERMANN, 2002).

\section{As construções compartilhadas de sentidos, opiniões e conhecimentos}

Pelo fato de termos organizado os grupos focais em dois momentos, sendo um deles de reflexão e registro individual, seguido da discussão coletiva, pudemos notar que alguns aspectos relacionados às temáticas surgiram a partir da interação entre as/os participantes, não estando presentes na dimensão individual ou estando presentes na dimensão individual de forma fragmentada, sem coordenação/relação com outras ideias.

Em um dos grupos focais realizados na primeira pesquisa, quando questionadas sobre suas principais motivações para participarem do curso de especialização em EA, percebemos duas participantes envolvidas em uma construção conjunta de significados. Elas iniciaram o diálogo falando da importância do certificado para a decisão de cursar a especialização em EA. Em um primeiro momento elas pareciam discordar sobre essa questão, mas o diálogo avançou no sentido de que o certificado emitido por uma universidade pública de renome reflete a credibilidade do curso, das instituições e dos profissionais envolvidos.

$\mathrm{Na}$ terceira pesquisa, uma das participantes do grupo focal afirmou que o ProMEA na Rede contribuiu para o aprendizado do grupo por meio do diálogo. Essa participante afirmou 
e citou exemplos que demonstravam as vezes em que houve o compartilhamento de propostas de atividades e experiências bem-sucedidas dentro do grupo. Essa perspectiva não estava presente nas anotações individuais dessa mesma participante, nos fazendo crer que ela emergiu exatamente a partir da interação com as demais pessoas naquele momento específico. A riqueza do que emerge na interação grupal geralmente extrapola as ideias prévias, surpreende, coloca novas categorias e formas de entendimento (GATTI, 2005).

No Projeto ProMEA na Rede percebemos que os grupos focais possibilitaram a construção compartilhada de sentidos e conhecimentos pelo grupo. Um exemplo está relacionado às estratégias para a mobilização da comunidade escolar em torno do tema ambiental. Ao ouvir os relatos das professoras, uma das gestoras propõe um caminho interessante para lidar com a dificuldade de envolvimento das/os demais professoras/es, funcionárias/os e comunidade de entorno da escola nos projetos ambientais. Ela defendeu a importância de iniciativas concretas que, quando divulgadas, geram envolvimento, mobilização e até mesmo autonomia das demais pessoas. Ainda nesse mesmo projeto, uma das professoras, ouvindo os depoimentos das demais sobre as dificuldades que enfrentaram para trabalhar com a temática e o enfoque da microbacia em suas atividades, e percebendo até certa frustração delas por esse motivo, comenta que os outros temas trabalhados (resíduos, economia de água e fauna) contribuem indiretamente para a qualidade da microbacia.

Em outro momento do grupo focal, uma das gestoras defendeu que a temática da microbacia precisa estar presente no currículo escolar para que seja efetivamente trabalhada com os alunos. Outra professora complementou essa colocação, afirmando que somente estar presente no currículo não garante a efetividade das ações, mas que as/os docentes precisam ter materiais didáticos disponíveis e formação adequada para realizar um trabalho com foco nessa temática. Por fim, o grupo todo concordou que esses três elementos precisam estar combinados, de forma que, mais uma vez, observamos que os grupos focais possibilitam construir sentidos, opiniões e conhecimentos compartilhados pelo grupo, a partir dos saberes, trajetórias e vivências individuais das pessoas.

Percebemos as habilidades das/os participantes do grupo em fornecer comentários suporte, contribuição, papel de comoderadoras/es, além de sua capacidade analítica. Segundo Gadamer (2005), o verdadeiro diálogo acontece no encontro entre pessoas dispostas a ouvirem-se mutuamente e expor suas opiniões à avaliação do outro. Ele não tem por objetivo derrubar os argumentos de uma pessoa, mas deixar o tema vir à luz, possibilitando que as/os participantes tenham a oportunidade de fazer uma autorreflexão sobre seus pontos de vista. Portanto, a verdade aparece na arte de olhar juntas e produzir um novo conceito.

$\mathrm{Na}$ segunda pesquisa, pudemos observar que, a partir de uma fala que valorizava a onça "porque é de extrema necessidade para a manutenção do equilíbrio do ecossistema e também porque épossivel a coexistência entre seres humanos e onça", outra pessoa se manifestou da seguinte forma: "ajuda equilibrar a fauna e a flora de maneira sustentável, melhora o convivio entre o homem e o meio ambiente, se respeitar o território dela'. Este exemplo remete a uma construção coletiva do saber. Conforme explicitado por Gatti (2005, p. 14), "há uma reelaboração de questões que é própria do trabalho particular do grupo mediante as trocas, os reasseguramentos mútuos, os consensos, os dissensos e que trazem luz sobre aspectos não detectáveis ou não reveláveis em outras condições”. 


\section{Emergência de informações e sentidos complementares}

Os resultados obtidos por meio dos grupos focais também nos permitiram identificar a emergência de informações/opiniões complementares, ou seja, que não estavam propostas nos questionários iniciais. Muitas vezes, essas informações são bastante relevantes e, pelo fato de serem resultado tanto da livre manifestação das/os participantes quanto da interação dentro do grupo, não estão presentes em outras técnicas de coleta de dados, como nas entrevistas individuais e nos questionários.

Em um dos grupos focais do CESCAR, duas participantes revelaram que houve uma postura de discriminação e segregação por parte de alguns participantes da especialização com relação àqueles da extensão, que eram tratados com desprezo porque não tinham formação acadêmica. Na pesquisa do semiárido baiano, foi possível perceber, a partir das falas, a junção de memórias e sentimentos que não são expressos quando o questionamento é apresentado na forma escrita. Em uma questão sobre o viver na caatinga, nas respostas escritas, as pessoas expressaram, principalmente, as dificuldades vividas. Porém, quando essa questão foi discutida, muitos sentimentos de amor, vínculos e memória se evidenciaram. Falou-se muito nas questões da criação tranquila dos filhos, do prazer de varrer um quintal, de criar animal, de comer frutas sem ser no prato. As falas iam se complementando e as memórias fluindo a construção de uma identidade sobre esse viver, o que dificilmente se caracterizaria apenas na forma escrita.

Nos grupos focais desenvolvidos no projeto ProMEA na Rede, percebemos que, apesar da proposta de discussão girar em torno das contribuições e desafios que o projeto trouxe para a EA escolar, emergiram algumas questões interessantes e extremamente relevantes, tanto para a pesquisa quanto em termos da avaliação do processo e de uma possível proposta para se pensar a continuidade desse projeto ou a implementação de projetos semelhantes em outros contextos. As educadoras mencionaram como bastante positiva a união e a cooperação dentro do grupo, algo que difere do que elas estão acostumadas a vivenciar no cotidiano escolar. Duas professoras citaram problemas pessoais ou dificuldades que enfrentaram à época do projeto e como as atividades desenvolvidas ajudaram-nas a superar essas dificuldades.

\section{Considerações Finais}

Consideramos que a técnica de grupos focais possui uma forte dimensão formativa diante de toda sua potência dialógica e reflexiva. Conforme observamos, o compartilhamento de experiências e de visões de mundo se fundem em um produto coletivo que pode acarretar novas posturas individuais e, por que não, coletivas. Nas três investigações pesquisadas, consideramos que a técnica cumpriu bem tanto a função avaliativa (descrita em publicações anteriores) quanto a investigativa e pode, portanto, ser utilizada para as duas finalidades. O potencial formativo foi observado em situações não intencionadas, de forma que acreditamos que o seu uso intencional com a finalidade formativa poderia potencializar tal resultado. 
Enquanto limites da técnica, destacamos o que ressalva Morgan (1996), que por mais harmonioso que o grupo esteja, a interação no grupo focal continua sendo um processo não natural, por ter uma condução da pessoa pesquisadora. Gatti (2005) também salienta que não existe um controle sobre o grupo e nem sobre os dados gerados; assim, eles podem não satisfazer a necessidade da pesquisa, de forma que, para emprego e escolha da técnica, existe a necessidade de flexibilidade e abertura do/a pesquisador/a.

Alguns/algumas autores/as sugerem realizar uma análise das posturas, gestos e silêncios dos participantes, para além das falas, nos grupos focais. Consideramos que essa análise seja de suma importância pois, conforme Barbour (2009, p. 176), "aquilo que não é dito pode ser tão importante quanto o que é dito nas discussões de grupo focal”. É necessário observar as possíveis causas dos silêncios, entre as quais a pessoa mediadora cortando a discussão ou se omitindo em fazer perguntas essenciais, além de contextos inapropriados ou situações desconfortáveis. Os silêncios que possuem potencial analítico são os que não são atribuídos às falhas da moderadora. São os "silêncios do estranhamento" ou da falta de relevância para o grupo participante ou os "silêncios da familiaridade", quando o assunto é tão cotidiano que não potencializa comentários. Se quem modera for sensível a essas nuances, pode melhor conduzir a discussão quando os notar ou ainda trazer isso para o foco da análise (BARBOUR, 2009).

Uma das limitações deste trabalho foi a dificuldade tanto em registrar quanto em interpretar essas manifestações não verbais. Na pesquisa realizada no CESCAR, em cada um dos grupos focais foi designada uma pessoa para registrar os gestos e posturas dos participantes. Esse registro, por si só, já constituiu a primeira dificuldade: a maior parte deles se refere a gestos e atitudes descontextualizados, como, por exemplo, "fulano cruzou os braços" ou "ciclano meneou a cabeça discordando". A interpretação desses registros tornou-se muito difícil, fazendo com que a pesquisadora não os considerasse em suas análises. Ainda assim, existe a necessidade de aprofundar os estudos sobre como interpretar posturas e gestos em pesquisas futuras, isto é, a linguagem não falada em grupos focais, de modo a possibilitar uma visão mais ampla sobre sua dinâmica grupal.

Nesse sentido, além da dificuldade em interpretar aspectos mais subjetivos dos seres humanos, como os corporais, também observamos que a técnica acaba por centralizar esforços nos aspectos relacionados à reflexão e diálogo e pouco explora os outros sentidos humanos em seus aspectos mais sensíveis e relacionais com o mundo, com a natureza. Existe uma forte tendência contemporânea em valorizar e incluir mais práticas corporais no processo de aprendizagem, diante do entendimento de que aprendermos através de todos os nossos sentidos. Porém, na forma atual que os grupos focais são empregados, ele é insuficiente tanto em relação à captura desses dados mais sensíveis como em relação a uma prática multissensorial.

Em resumo, buscamos ressaltar a ampliação e o aprofundamento que pode ser feito em relação à utilização dos grupos focais nos processos formativos dialógicos, diante da potencialidade de questões e aspectos educacionais que a técnica permite trabalhar. Porém, não deixamos de perceber e apontar alguns limites percebidos e, diante deles, incentivamos um melhor desenvolvimento da técnica para ampliar a expressão dos aspectos sensíveis humanos. 
Di Tullio, A.; Hofstatter, L. J. V.; Santos, S. A. M.; Oliveira, H. T.

\section{Referências}

BARBOUR, R. Grupos focais. Porto Alegre: Artmed, 2009.

BERTO, A. B. F.; CRIBB, S. L. S. P. A educação ambiental nos espaços formais de ensino: brinquedoteca virtual como instrumento para capacitação de professores. REMEA: revista eletrônica do mestrado em educação ambiental, Rio Grande, v. 21, p. 1-14, 2008.

BRASIL. Ministério do Meio Ambiente. ProFEA: programa nacional de formação de educadoras(es) ambientais: por um Brasil educado e educando ambientalmente para a sustentabilidade. Brasília: MMA, 2006.

CARVALHO, I. C.; MHULE, R. P. Intenção e atenção nos processos de aprendizagem: por uma educação ambiental "fora da caixa”. Ambiente \& Educação: revista de educação ambiental, Rio Grande, v. 21, n. 1, p. 26-40, 2016.

CARVAlHO, L. M.; TOMAZELLO, G.; OLIVEIRA, H. T. Pesquisa em educação ambiental: panorama da produção brasileira e alguns de seus dilemas. Cadernos Cedes, Campinas, v. 29, n. 77, p. 13-27, jan/abr. 2009.

CATANI, A. M. A configuração do campo de pesquisa em educação ambiental. Pesquisa em Educação Ambiental, Rio Claro, v. 4, n. 2, p. 27-47, 2009. Conferência apresentada no V Encontro de Pesquisa em Educação Ambiental, 2009, São Carlos, SP.

CONTRERAS, J. A autonomia de professores. 2. ed. São Paulo: Cortez, 2012.

CRUZ NETO, O.; MOREIRA, M. R.; SUCENA, L. F. M. Grupos focais e pesquisa social qualitativa: o debate orientado como técnica de investigação. In: ENCONTRO DA ASSOCIAÇÃO BRASILEIRA DE ESTUDOS POPULACIONAIS, 13., 2002, Ouro Preto. Anais [...]. Belo Horizonte: ABEP, 2002. p. 1-26.

DILLON, J.; WALS, A. E. J. On the danger of blurring methods, methodologies and ideologies in environmental education research. Environmental Education Research, Abingdon, v. 12, n. 3-4, p. 549-558, 2006. DOI: https://doi. org/10.1080/13504620600799315.

DI TULLIO, A.; OLIVEIRA, H. T. Sentidos atribuídos por professoras do ensino básico a sua formação no processo de atuação como educadoras ambientais. REMEA: revista eletrônica do mestrado em educação ambiental, Rio Grande, v. 31, p. 271-291, 2014.

FERNANDES, J. A. B.; KAWASAKI, C. S. A pesquisa em educação ambiental e questões metodológicas: relato do grupo de discussão de pesquisa no VI EPEA. Pesquisa em Educação Ambiental, Rio Claro, v. 7, n. 2, p. 91-103, 2012.

FIEN, J. Advancing sustainability in higher education: issues and opportunities for research. International Journal of Sustainability in Higher Education, Bingley, v. 3, n. 3, p. 243-253, 2002. 
FRACALANZA, H. et al. A educação ambiental no Brasil: panorama inicial da produção acadêmica. In: ENCONTRO DE PESQUISA EM EDUCAÇÃO EM CIÊNCIAS, 5., 2005, Bauru. Anais [...]. Bauru: ABRAPEC, 2005. 1 CD-ROM.

FREIRE, P. À sombra desta mangueira. 10. ed. São Paulo: Olho d’Água, 2012.

FREIRE, P. Extensão ou comunicação? 8. ed. Rio de Janeiro: Paz e Terra, 1985.

FREIRE, P. Pedagogia da esperança: um reencontro com a pedagogia do oprimido. Rio de Janeiro: Paz e Terra, 1994.

FREIRE, P. Pedagogia da indignação: cartas pedagógicas e outros escritos. São Paulo: Editora UNESP, 2000.

FREIRE, P. Pedagogia do oprimido. 8. ed. Rio de Janeiro: Paz e Terra, 1980.

GADAMER, H-G. Verdade e método. 7. ed. Petrópolis: Vozes, 2005. v. 1.

GADAMER, H-G. La educación es educarse. Revista de Santander: segunda época, Santander, n. 6, p. 90-109, 2011. Disponível em: http://www.uis.edu.co/webUIS/es/ mediosComunicacion/revistaSantander/revista6/nuevasCorrientesIntelectuales.pdf. Acesso em: 14 ago. 2012.

GASKELL, G. Entrevistas individuais e grupais. In: BAUER, W. M.; GASKELL, G. (org.). Pesquisa qualitativa com texto, imagem e som: um manual prático. 10 ed. Petrópolis: Vozes, 2010. p. 64-89.

GATTI, B. A. Grupo focal na pesquisa em ciências sociais e humanas. Brasília: Liber Livros, 2005.

GIROUX, H. A. Os professores como intelectuais: rumo a uma pedagogia crítica da aprendizagem. Porto Alegre: Artmed, 1997.

GUIMARÃES, M. A formação de educadores ambientais. Campinas: Papirus, 2004. HERMANN, N. Hermenêutica e educação. Rio de Janeiro: DP\&A, 2002.

HOFSTATTER, L. J. V. O imagético de uma comunidade caatingueira e os sentidos atribuídos à onça em um processo formativo de educação ambiental crítica. 2013. 199 f. Dissertação (Mestrado em Ecologia e Recursos Naturais) - Universidade Federal de São Carlos, São Carlos, 2013.

INGOLD, T. Da transmissão da representação à educação da atenção. Educação, Porto Alegre, v. 33, n. 1, p. 6-25, 2010.

KITZINGER, J.; BARBOUR, R. S. Introduction: the challenge and promise of focus groups. In: BARBOUR, R. S.; KITZINGER, J. Developing focus groups research: politics, theory and practice. London: Sage, 1998. p. 1-20.

KRUEGER, R. A. Focus groups: a practical guide for applied research. 2. ed. Thousand Oaks: Sage, 1994. 
LAWN, C. Compreender Gadamer. 2. ed. Petrópolis: Vozes, 2010.

MORAES, R.; GALIAZZI, M. C. Análise textual discursiva. 2. ed. rev. Ijuí: Unijuí, 2011.

MORGAN, D. L. Focus groups as qualitative research. 2. ed. Thousand Oaks: Sage, 1996.

NEIMAN, Z.; RABINOVICH, A. A educação ambiental através do ecoturismo: o diferencial das atividades de contato dirigido com a natureza. Pesquisa em Educação Ambiental, Rio Claro, v. 3, n. 2, p. 77-101, 2008.

NÓVOA, A. Formação de professores e profissão docente. In: NÓVOA, A. (org.). Os professores e sua formação. Lisboa: Publicações Dom Quixote: Instituto Inovação Educacional, 1992. p. 13-33.

PAYNE, P. "Ways of doing”, learning, teaching and researching. Canadian Journal of Environmental Education, Thunder Bay, v. 10, n. 1, p. 108-124, 2005.

PAYNE, P. G. Framing research: conceptualization, contextualization, representation and legitimation. Pesquisa em Educação Ambiental, Rio Claro, v. 4, n.2, p. 49-77, 2009.

PAYNE, P. G.; WATTCHOW, B. Phenomenological deconstruction, slow pedagogy and the corporeal turn in wild environmental/outdoor education. Canadian Journal of Environmental Education, Thunder Bay, v. 14, p. 15-32, 2009.

PINK, S. Doing sensory ethnography. London: Sage, 2009.

REID, A.; SCOTT, W. Researching education and the environment: retrospect and prospect. Environmental Education Research, Abingdon, v. 12, n. 3-4, p. 571-588, 2006.

ROBOTTOM, I.; HART, P. Research in environmental education: engaging the debate. Geelong: Deakin University Press, 1993.

ROLLEMBERG, A. T. V. M. Entrevistas de pesquisa: oportunidades de coconstrução de significados. In: BASTOS, L. C.; SANTOS, W. S. (org.). A entrevista na pesquisa qualitativa: perspectivas em análise da interação. Rio de Janeiro: Quartet: Faperj, 2013. p. 37-48.

SANTOS, S. A. M. Políticas públicas de formação de educadores ambientais: análise do processo de constituição do coletivo educador de São Carlos, Araraquara, Jaboticabal e região - CESCAR. 2010. 217 f. Tese (Doutorado em Ciências da Engenharia Ambiental) Escola de Engenharia de São Carlos, Universidade de São Paulo, São Carlos, 2010.

STEIL, C. A.; CARVALHO, I. C. Epistemologias ecológicas: delimitando um conceito. Mana, Rio de Janeiro, v. 20, n. 1, p. 163-183, 2014. DOI: https://doi.org/10.1590/S010493132014000100006.

TESTA, E. Hermenêutica filosófica e história. Passo Fundo: UPF, 2004. 
THRIFT, N. Non-representational theory: space, politics, affect. New York: Routledge, 2008.

TOZONI-REIS, J. R. Ação coletiva na produção dos conhecimentos: compreendendo o processo grupal. In: TOZONI-REIS, M. F. C. (org.) A pesquisa-ação-participativa em educação ambiental: reflexões teóricas. São Paulo: Annablume: FAPESP; Botucatu: Fundibio, 2007. p. 83-119.

TOZONI-REIS, M. F. C.; SOUZA, D. C. Pesquisa em educação ambiental e questões metodológicas: uma discussão coletiva. Pesquisa em Educação Ambiental, Rio Claro, v. 9, n. 1, p. 133-143, 2014.

Artigo recebido em 06/04/2018. Aceito em 16/09/2018.

Contato: Fubá Educação Ambiental e Criatividade, Rua Dona

Alexandrina, 1388, sala 3, São Carlos, SP, 13560-290, Brasil. 
